\title{
Validation of PfSNP-LAMP-Lateral Flow Dipstick for Detection of Single Nucleotide Polymorphism Associated with Pyrimethamine Resistance in Plasmodium falciparum
}

\author{
Suganya Yongkiettrakul ${ }^{1}$, Fassou René Kolié ${ }^{2}$, Darin Kongkasuriyachai ${ }^{1}$, \\ Jetsumon Sattabongkot ${ }^{3}$ (D), Wang Nguitragool ${ }^{4}$, Namfon Nawattanapaibool ${ }^{2}$, \\ Chayanut Suansomjit ${ }^{3}$, Saradee Warit ${ }^{1}$, Niwat Kangwanrangsan ${ }^{5}$ and Sureemas Buates ${ }^{2, *}$ \\ 1 National Center for Genetic Engineering and Biotechnology (BIOTEC), National Science and Technology \\ Development Agency (NSTDA), Pathum Thani 12120, Thailand; suganya.yon@biotec.or.th (S.Y.); \\ darin@biotec.or.th (D.K.); saradee@biotec.or.th (S.W.) \\ 2 Department of Microbiology, Faculty of Science, Mahidol University, Bangkok 10400, Thailand; \\ fassourenek@gmail.com (F.R.K.); namfon.naw@gmail.com (N.N.) \\ 3 Mahidol Vivax Research Unit, Faculty of Tropical Medicine, Mahidol University, Bangkok 10400, Thailand; \\ jetsumon.pra@mahidol.ac.th (J.S.); chayanut_titti@outlook.com (C.S.) \\ 4 Department of Molecular Tropical Medicine and Genetics, Faculty of Tropical Medicine, Mahidol University, \\ Bangkok 10400, Thailand; wang.ngu@mahidol.edu \\ 5 Department of Pathobiology, Faculty of Science, Mahidol University, Bangkok 10400, Thailand; \\ niwat.kan@mahidol.ac.th \\ * Correspondence: sbuates@hotmail.com; Tel.: +66-2-201-5671
}

Received: 7 October 2020; Accepted: 11 November 2020; Published: 13 November 2020

\begin{abstract}
The loop-mediated isothermal amplification coupled with lateral flow dipstick (PfSNP-LAMP-LFD) was recently developed to detect single nucleotide polymorphism (AAT $\rightarrow$ ATT), corresponding to substitution of asparagine to isoleucine at amino acid position 51 in the P. falciparum $d h f r$-ts gene associated with antifolate resistance. In this present study, the PfSNP-LAMP-LFD was validated on 128 clinical malaria samples of broad ranged parasite densities (10 to 87,634 parasites per microliter of blood). The results showed $100 \%$ accuracy for the detection of single nucleotide polymorphism for N51I mutation. Indeed, the high prevalence of N51I in the Pfdhfr-ts gene detected in the clinical samples is in line with reports of widespread antifolate resistant $P$. falciparum in Thailand. The relationship between enzyme choice and reaction time was observed to have an effect on PfSNP-LAMP-LFD specificity; however, the method yielded consistent results once the conditions have been optimized. The results demonstrate that PfSNP-LAMP-LFD is a simple method with sufficient sensitivity and specificity to be deployed in routine surveillance of antifolate resistance molecular marker and inform antimalarial management policy.
\end{abstract}

Keywords: dihydrofolate reductase; loop-mediated isothermal amplification-lateral flow dipstick (LAMP-LFD); malaria detection; Plasmodium falciparum; pyrimethamine; antifolate resistance; drug resistance; single nucleotide polymorphism

\section{Introduction}

The global malaria morbidity and mortality have decreased substantially over the past decades, yet malaria still remains a significant global health threat. More than 228 million malaria cases and 405,000 deaths were reported in 2019 [1]. The increasing threats of multidrug-resistant malaria have raised the urgency to accelerate the global malaria elimination agenda. The Greater Mekong Subregion 
is the hotspot for multidrug-resistant malaria, where resistant parasites have emerged and spread across the globe. The sulfadoxine-pyrimethamine (SP) combination is recommended by the World Health Organization (WHO) to be used as seasonal malaria chemoprevention (SMC) in children under 5 years and as an intermittent preventive therapy (IPT) in pregnant women in areas of moderate or high transmission of Plasmodium falciparum $[2,3]$. SP blocks the enzymes in the folate synthesis pathway of P. falciparum, the dihydropteroate synthetase (DHPS), and the dihydrofolate reductase (DHFR), respectively $[4,5]$. Pyrimethamine resistance arose from specific point mutations resulting in amino acid substitutions in the DHFR at positions N51I, C59R, S108N/T, and I164L [6-12].

The surveillance of molecular markers associated with antimalarial resistance can be informative for evidence-based policy decision on antimalarial management. The prevalence of known single nucleotide polymorphisms (SNPs) attributed to pyrimethamine resistance was considered during the development of SNP-loop-mediated isothermal amplification coupled with lateral flow dipstick (PfSNP-LAMP-LFD). While S108N is the most common SNP identified; however, single mutation is rarely found in pyrimethamine resistant parasites [13-15]. In fact, stepwise accumulation of Pfdhfr has been described with an initial S108N mutation and sequential additional mutations at N51I and/or C59R, and I164L [15]. The high A + T content of P. falciparum genome represented technical challenges in the design of a SNP-LAMP primer set. The position of N51I SNP allowed for the best primer design and development of a robust PfSNP-LAMP-LFD that could capture most of the circulating pyrimethamine-resistant parasite population including double mutant (N51I + S108N), triple mutant $(\mathrm{N} 51 \mathrm{I}+\mathrm{C} 59 \mathrm{R}+\mathrm{S} 108 \mathrm{~N})$, and quadruple mutant (N51I + C59R + S108N + I164L).

Loop-mediated isothermal amplification (LAMP) is a nucleic acid amplification method performed under single temperature that is relatively simple, cost-effective, and time-efficient [16]. Key features of LAMP are the proper design of four different primers that bind to six different regions of the target sequence and the use of Bst DNA polymerase with strong strand displacement activity which eliminate the need for double strand denaturing steps compared to traditional PCR-based method. The use of four primers in LAMP method can quickly accumulate a large amount of LAMP products with characteristic stem-loop concatemeric structures and pyrophosphate by-products, which can form visible white precipitants in the presence of magnesium. Commonly used methods for visualizing LAMP products include gel electrophoresis, real-time turbidimetry, SYBR green dye, and a lateral flow dipstick (LFD). The use of gel electrophoresis can distinguish specific amplification from non-specific products but it is more time consuming, while the visualization of SYBR green dye intercalated LAMP products is simple but can be subjective. Real-time turbidity resulting from precipitation of magnesium-pyrophosphate can be used; however, it requires the purchase and maintenance of a turbidimeter. The LAMP method does not require specialized equipment, so it has the potential to be used in molecular diagnostic at point-of-care or in surveillance programs. Indeed, LAMP test kits are available for the detection variety of pathogens such as COVID-19, E. coli O157, and tuberculosis [17].

There have been numerous reports demonstrating comparable or even improved performances of LAMP-based protocols compared to PCR-based protocols for species detection of malaria parasites [18-21]. In recent years, several LAMP-based single nucleotide polymorphism (SNP) detection protocols with different result readouts have been reported. LAMP coupled one-step strand displacement (LAMP-OSD), and LAMP combined with allele-selective oligonucleotide hybridization (LAMP-ASO), relied on the use of allele-specific probe hybridization to detect amplified LAMP products [22,23]. Probe-enhanced LAMP (PE-LAMP) utilized the loop-primer as allele-specific (AS) primer that bound to target allele or SNP and preferentially amplified the target sequence, while the LAMP-SNP utilized the FIP and BIP inner primers as sequence-specific primers to preferentially amplify the target sequence [24-26]. Peptide nucleic acid-locked nucleic acid-mediated LAMP (PNA-LNA LAMP) utilized peptide nucleic acid as a blocking agent to prevent the amplification of a specific allele or SNP [27]. Compared to other LAMP-AS or LAMP-SNP protocols, which relied on colorimetric change observed by naked eyes or in real-time PCR equipment, the PfSNP-LAMP-LFD used the same read out format as most commercially available rapid diagnostic tests to detect N51I mutation in the 
Pfdhfr-ts gene [26]. In this present study, the PfSNP-LAMP-LFD was further optimized and evaluated on clinical malaria samples, in order to validate its application as an alternative test for point-of-care diagnostics and for the molecular surveillance of malaria drug-resistant biomarkers.

\section{Materials and Methods}

\subsection{Clinical Blood Sample Collection and Genomic DNA Extraction}

Blood samples were collected from malaria patients presented at the malaria clinics in Thailand between 2013 and 2018. The prevalence of P. falciparum in this area was approximately 3.7\%, as determined by PCR [28]. Patients were diagnosed with malaria based on microscopy examination of thick and thin blood films by laboratory technicians and received the standard treatment according to the national treatment guidelines. Patients with uncomplicated P. falciparum infection were invited to participate in the study after providing informed consent, following an approved protocol by the Ethics Committee of the Faculty of Tropical Medicine, Mahidol University (Protocol number: TMEC 11-030, TMEC 16-010, and TMEC 18-009). Briefly, blood sample was collected from each patient by finger prick using heparinized capillary tubes. A volume of $100 \mu \mathrm{L}$ of the packed red blood cells was stored in the freezer. Genomic DNA extraction was performed on the frozen blood samples using ${ }^{\circledR}$ QIAamp DNA Blood minikit (Germantown, MD, USA), as described by the manufacturer's protocol. A total of $2 \mu \mathrm{L}$ of eluted DNA was used directly for PfSNP-LAMP-LFD to detect N51I SNP on the dhfr-ts gene associated with pyrimethamine resistance and for nested PCR to confirm malaria species based on the detection of the $18 \mathrm{~S}$ ribosomal RNA gene [29].

\subsection{DNA Sequencing}

Briefly, the amplified Pfdhfr-ts gene products of P. falciparum clinical samples were obtained by PCR using specific primer pairs (Forward-Pfdhfr; $5^{\prime}$-GATGGAACAAGTCTGCGACGTTTTCG-3' and Reverse-Pfdhfr; $5^{\prime}$-CCCAAGTAAAACGATTAGATCTTCAACTTT-3'). PCR reactions were conducted in a $25 \mu \mathrm{L}$ reaction mixture using the following condition: initial denaturation at $95^{\circ} \mathrm{C}$ for $2 \mathrm{~min}$, followed by 35 cycles of $95{ }^{\circ} \mathrm{C}$ for $1 \mathrm{~min}, 5{ }^{\circ} \mathrm{C}$ for $1 \mathrm{~min}$, and $72{ }^{\circ} \mathrm{C}$ for $1 \mathrm{~min}$, with a final extension at $72{ }^{\circ} \mathrm{C}$ for $5 \mathrm{~min}$. A PCR purification kit (NIPPON Genetics, Tokyo, Japan) was used to obtain purified PCR products for DNA sequencing. The sequencing reactions were conducted with the BigDye Terminator Version 3.1 Cycle-Sequencing Kit (Applied Biosystems, Foster City, CA, USA), using the same primers as above. The DNA sequences were analyzed with the Bioedit program.

\subsection{Recombinant Plasmid Construction}

The pUC18-Pfdhfr-TM4/8.2 containing the wild-type SNP (AAT) of the Pfdhfr-ts gene was used as a negative control. The pUC18-Pfdhfr-V1/S containing the mutant SNP (ATT) corresponding to the N51I mutation was used as positive control. The V1/S strain of $P$. falciparum is considered to be highly resistant to pyrimethamine, with 4 reported mutations (N51I + C59R + S108N + I164L) in the Pfdhfr-ts gene. These two plasmids were constructed as previously described [21].

\subsection{PfSNP-LAMP-LFD Conditions}

The $25 \mu \mathrm{L}$-volume of PfSNP-LAMP reaction mixture contained the following components: $2 \mu \mathrm{M}$ each of $P f$-snp-FIP and $P f$-snp-BIP primers, $0.2 \mu \mathrm{M}$ each of $P f$-snp-F3 and $P f$-snp-B3 primers, 1X isothermal amplification buffer $\left(20 \mathrm{mM}\right.$ Tris- $\mathrm{HCl}, 10 \mathrm{mM}\left(\mathrm{NH}_{4}\right)_{2} \mathrm{SO}_{4}, 10 \mathrm{mM} \mathrm{KCl}, 2 \mathrm{mM} \mathrm{MgSO}_{4}$, $0.1 \%$ Triton $\mathrm{X}-100, \mathrm{pH} 8.8$ ), $0.4 \mathrm{M}$ betaine (USB Corporation, Cleveland, $\mathrm{OH}, \mathrm{USA}$ ), $8 \mathrm{mM} \mathrm{MgSO}_{4}$ (Sigma-Aldrich, St. Louis, MO, USA), $1.4 \mathrm{mM}$ dNTP mix (Promega, Madison, WI, USA), 8 units of Bst DNA polymerase, a large fragment or Bst 2.0 DNA polymerase or Bst 2.0 WarmStart DNA polymerase (New England Biolab, Ipswich, MA, USA), and $2 \mu \mathrm{L}$ of DNA sample. The design of the PfSNP-LAMP primer set was also previously described [26]. For negative and positive control reactions, 20 nanograms of pUC18-Pfdhfr-TM4/8.2 and pUC18-Pfdhfr-V1/S were used, respectively. 
For optimization, LAMP reactions were performed at $60-63{ }^{\circ} \mathrm{C}$ and observed for $60-90$ min and LAMP product signals were monitored using Loopamp Realtime Turbidimeter at $650 \mathrm{~nm}$ wavelength (LA-320C, Eiken Chemical Co., Ltd., Tokyo, Japan). For the validation of clinical samples, PfSNP-LAMP reactions were performed using Bst 2.0 WarmStart DNA polymerase (New England Biolab, Ipswich, MA, USA) at $63{ }^{\circ} \mathrm{C}$ for $75 \mathrm{~min}$. Then, $20 \mathrm{pmol} P f$-FITC-probes was directly added to the reaction and allowed to hybridize with products at $63^{\circ} \mathrm{C}$ for $5 \mathrm{~min}$. Subsequently, $8 \mu \mathrm{L}$ of the hybridized PfSNP-LAMP-probe were transferred into a new Eppendorf tube containing $120 \mu \mathrm{L}$ of room-temperature assay buffer (Milenia ${ }^{\circledR}$ GenLine HybriDetect, GieBen, Germany). The LFD strip was dipped into the assay solution for $5 \mathrm{~min}$ to allow the solution to migrate by chromatography effect. Two bands were observed on the control line and the test line of the LFD strip for samples with N51I mutation. One band was observed on the control line, representing a negative result for negative sample (no DNA template) or wild-type SNP sample. If no signal appeared on the control line, then the result was invalid.

\section{Results}

\subsection{Effects of Enzyme and Reaction Time on PfSNP-LAMP Sensitivity and Specificity}

Bst 2.0 DNA polymerase and Bst 2.0 WarmStart DNA polymerase are homologues of Bst DNA polymerase large fragment that have been designed for improvements in amplification speed, thermostability, and salt tolerance, in order to increase the quantity of product, according to the manufacturer's product descriptions. Here, we compared the effect of enzyme choice on PfSNP-LAMP reactions. The PfSNP-LAMP reactions were evaluated under varying temperatures from 60 to $63^{\circ} \mathrm{C}$ for up to 90 min using Loopamp Realtime Turbidimeter.

Figure 1A-D show the effects of temperature, choice of enzyme, and length of observed reaction time, on the sensitivity and specificity of PfSNP-LAMP. Signals represented amplified products using Bst, Bst 2.0, and Bst 2.0 WarmStart DNA polymerases in the reactions with either pUC18-Pfdhfr-V1/S (Lines 1, 3, and 5) or pUC18-Pfdhfr-TM4/8.2 (Lines 2, 4, and 6) as DNA templates.

The overall observation suggested that all three versions of $B s t$ DNA polymerases could distinguish the V1/S SNP (ATT, isoleucine) from TM4/8.2 SNP (AAT, asparagine) when performed at the optimal temperature of $63{ }^{\circ} \mathrm{C}$. Signals began to appear around the $60-\mathrm{min}$ mark and reached the optimal time around the 75-min mark. The appearance time of peak signal was dependent on the amount of the starting DNA templates in the reaction. The signal intensities were similar for all reaction conditions and concentrations of templates tested.

Non-specific signals could be observed from samples with pUC18-Pfdhfr-TM4/8.2 when using Bst DNA polymerase (Line 2) for all temperatures. Non-specific signals clustered closer to the true positive signals (Lines, 1, 3, and 5, near the 60-min mark) when performed at the lower range of temperature at $60{ }^{\circ} \mathrm{C}$ (Figure 1A) and $61^{\circ} \mathrm{C}$ (Figure 1B), thus, reducing the cut-off window for distinguishing between non-specific signals from true positive signals. There were greater separations between true positive signals (Lines 1, 3, and 5, below the 60-min cut-off mark) and non-specific signals (Lines 2 and 4, above the 60 -min cut-off mark) when reactions were performed at 62 and $63{ }^{\circ} \mathrm{C}$ as shown in Figure $1 \mathrm{C}$ and Figure 1D, respectively. The optimal reaction temperature and enzyme combination to yield the best separation of true positive signals, and non-specific signals were observed at $63{ }^{\circ} \mathrm{C}$ for $B s t 2.0$ WarmStart DNA polymerase, with a reaction time window between 60-75 min.

To further explore the detection limit of PfSNP-LAMP reaction with Bst 2.0 WarmStart DNA polymerase, reactions were performed at $63^{\circ} \mathrm{C}$ by using ten-fold serial dilutions of DNA templates from 0.002 to $200 \mathrm{ng}$. No signal was observed from pUC18-Pfdhfr-TM4/8.2 up to the 75-min mark, as expected for a negative control. However, a non-specific signal could be observed with $200 \mathrm{ng}$ of pUC18-Pfdhfr-TM4/8.2 above the 77-min mark, which was beyond the optimal range of reading time between 60-75 min (Figure 2A). The PfSNP-LAMP showed a dose response effect for detection of mutant SNP, where samples with higher concentration of pUC18-Pfdhfr-V1/S showed a faster appearance of peak signals, corresponding to accumulation of amplified products (Figure 2B), as expected. 
The detection limit for PfSNP-LAMP reaction using Bst 2.0 WarmStart DNA polymerase appeared to be $0.02 \mathrm{ng}$ of pUC18-Pfdhfr-V1/S $\left(\sim 5.5 \times 10^{5}\right.$ copy number $)$. These results were consistent with the detection limit of pUC18-Pfdhfr-V1/S observed in previous report [26]. Furthermore, the PfSNP-LAMP reaction products were resolved on gel electrophoresis where the characteristic ladder pattern was observed for reactions amplified from pUC18-Pfdhfr-V1/S but not from pUC18-Pfdhfr-TM4/8.2 (data not shown). The amplified PfSNP-LAMP products were visualized on LFD strips, as shown in Figure 3.
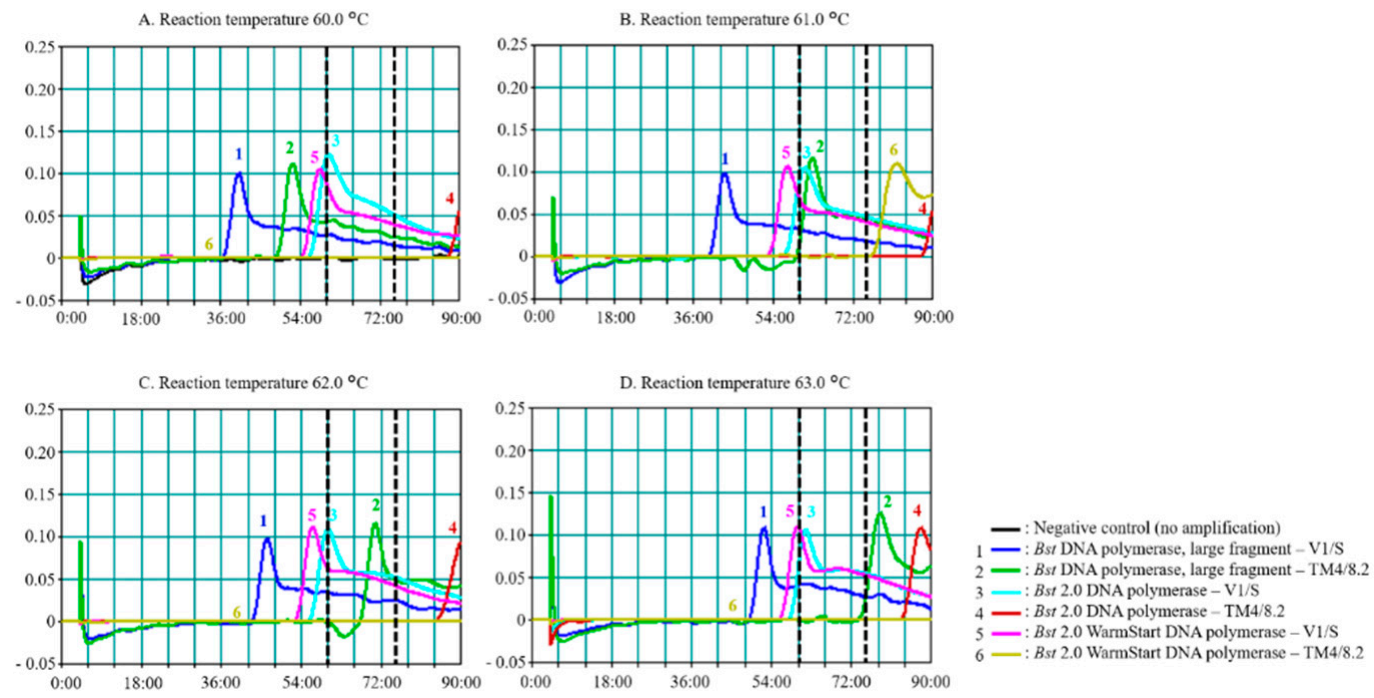

Figure 1. Effects of temperature and enzyme choice on SNP-loop-mediated isothermal amplification (PfSNP-LAMP) performance to detect mutant single nucleotide polymorphism (SNP) in the Pfdhfr-ts gene. Reactions were performed at $(\mathrm{A}) 60.0^{\circ} \mathrm{C}$, (B) $61.0^{\circ} \mathrm{C},(\mathrm{C}) 62.0^{\circ} \mathrm{C}$, and (D) $63.0^{\circ} \mathrm{C}$. A total of $20 \mathrm{ng}$ of template DNA was used for each reaction. Lines 1 and 2 were reactions using Bst DNA polymerase large fragment on pUC18-Pfdhfr-V1/S (mutant SNP) and pUC18-Pfdhfr-TM4/8.2 (wild-type $\mathrm{SNP}$ ), respectively. Lines 3 and 4 were reactions using Bst 2.0 DNA polymerase on V1/S and TM4/8.2, respectively. Lines 5 and 6 were reactions using Bst 2.0 WarmStart DNA polymerase on V1/S and TM4/8.2, respectively. The 60-min and 75-min markers were shown with dashed lines. Signals were read by Loopamp Realtime Turbidimeter for up to $90 \mathrm{~min}$. Similar results were obtained in three independent experiments.
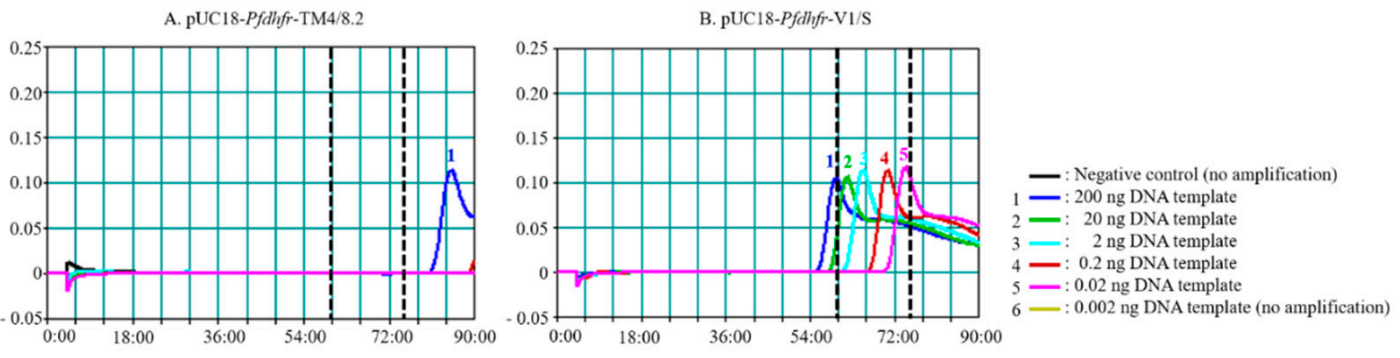

Figure 2. Detection limit of PfSNP-LAMP reaction using Bst 2.0 WarmStart DNA polymerase. The amplification reactions were performed at $63{ }^{\circ} \mathrm{C}$ using 10 -fold serial dilutions (0.002 to $200 \mathrm{ng}$ ) of (A) pUC18-Pfdhfr-TM4/8.2 and (B) pUC18-Pfdhfr-V1/S. Similar experiments were performed independently in five replications. 


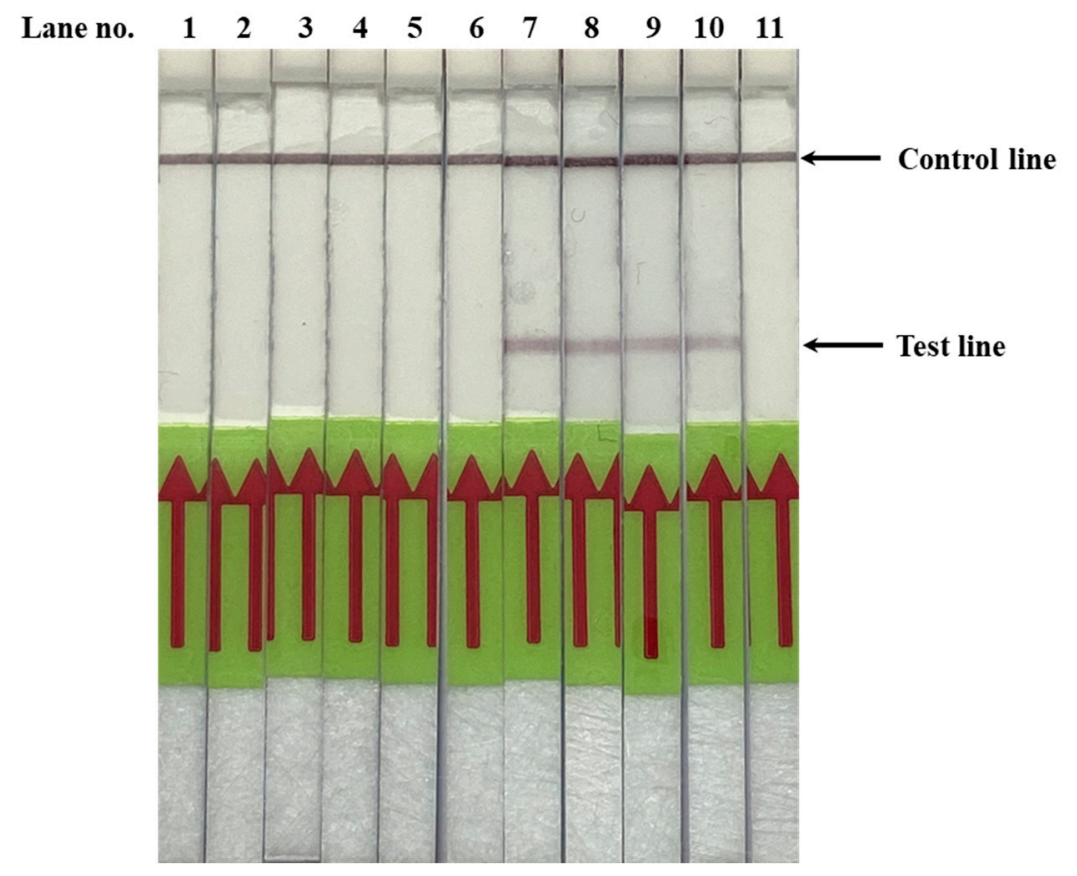

Figure 3. Representative results for SNP-loop-mediated isothermal amplification combined with later flow dipstick (PfSNP-LAMP-LFD) assay. The products from PfSNP-LAMP reactions were hybridized with labelled probes and applied to the LFD strips for visualization. Lane 1 was a negative control (no DNA template). Lanes 2-6 were pUC18-Pfdhfr-TM4/8.2 (wild-type SNP) diluted at $20 \mathrm{ng}, 2 \mathrm{ng}$, $0.2 \mathrm{ng}, 0.02 \mathrm{ng}$ and $0.002 \mathrm{ng}$, respectively. Lanes 7-11 were pUC18-Pfdhfr-V1/S (mutant SNP) diluted at $20 \mathrm{ng}, 2 \mathrm{ng}, 0.2 \mathrm{ng}, 0.02 \mathrm{ng}$, and $0.002 \mathrm{ng}$, respectively. For positive detection of the SNP mutation, both the control and test lines must appear on the strip. For wild-type SNP, only the control line appears. If no signal appears on the control line, then the result is invalid.

\subsection{Validation of PfSNP-LAMP-LFD in Clinical Blood Samples from Malaria Patients}

A total of 128 clinical blood samples from malaria clinics in Thailand were used to validate PfSNP-LAMP-LFD. There were 55 P. falciparum samples and 73 P. vivax samples, the latter served as additional negative control samples. A recent investigation of $P$. falciparum samples collected in Thailand between 2008-2016 showed high prevalence of N51I among the surveyed parasites, where up to $11 \%$ were triple mutants (N51I + C59R + S108N) and $83 \%$ were quadruple mutants (N51I + C59R $+\mathrm{S} 108 \mathrm{~N}+\mathrm{I} 164 \mathrm{~L})[30,31]$. Due to limited availability of clinical samples with wild-type Pfdhfr-ts in Thailand, we included $20 \mathrm{ng}$ of genomic DNA from two different lab strains, with wild-type Pfdhfr-ts (TM4/8.2 and NF54) as negative controls for this validation study.

The validation results are summarized in Table 1 . The PfSNP-LAMP-LFD reactions correctly detected SNP associated with pyrimethamine resistance (ATT, N51I) in 55 out of 55 P. falciparum samples, with parasite density from 10 to 87,634 parasites per microliter $(\mathrm{P} / \mu \mathrm{L})$ of blood $(100 \%$ accuracy), while no signal was observed in all $73 P$. vivax samples with parasite density from 9 to $12,632 \mathrm{P} / \mu \mathrm{L}$ and $P$. falciparum strain NF54 sample (100\% specificity). The range of parasite density used in this study was sufficiently broad to allow insights into the performance of PfSNP-LAMP-LFD in actual clinical settings. The performance observed for PfSNP-LAMP-LFD was comparable to the typical performance range seen with expert level malaria microscopy $(50-500 \mathrm{P} / \mu \mathrm{L})$, commercially available rapid diagnostic test (RDT, 100-200 P/ $\mu \mathrm{L}$ ), and other nucleic acid-based detection methods (1-5 P/ $\mu \mathrm{L}$ ) [32-34]. DNA sequencing confirmed that all of the 55 P. falciparum samples contained the mutant SNP in the Pfdhfr-ts gene. In addition, C59R and S108N mutations were also observed in these samples; however, it is noted that SNP associated with I164L in the Pfdhfr-ts gene was not examined. Nonetheless, these observations were in agreement with other studies that also reported 
high prevalence of N51I, C59R, S108N, and I164L mutations in the Pfdhfr-ts gene, among circulating parasites in the Greater Mekong Subregion [30,31]. Representative samples of PfSNP-LAMP-LFD validation on clinical malaria samples tested are shown in Figure 4.

Table 1. Summary of results from PfSNP-LAMP-LFD detection of SNP for N51I mutation in 128 clinical malaria samples from Thailand categorized by malaria species and parasite density. Samples with SNP for N51I mutation were corroborated by DNA sequencing.

\begin{tabular}{lcccc}
\hline & No. of Samples & $\mathbf{( P ~ \% )}$ & Parasite Density $(\mathbf{P} / \boldsymbol{\mu L})^{\mathbf{1}}$ & $\begin{array}{c}\text { PfSNP-LAMP-LFD } \\
\text { (N51I) }\end{array}$ \\
\hline & 2 & ND & ND & 2 \\
& 5 & $>0.2$ & $>10,000$ & 5 \\
P. falciparum $^{2}$ & 25 & $>0.02-0.2$ & $>1000-10,000$ & 25 \\
& 10 & $>0.004-0.02$ & $>200-1000$ & 10 \\
& 6 & $>0.0002-0.004$ & $>100-200$ & 6 \\
P. vivax & 3 & $0.0001-0.0002$ & $>50-100$ & 4 \\
& 4 & $<0.0001$ & ND & 0 \\
\hline TOTAL & 1 & ND & $<10-12,000$ & 0 \\
\hline
\end{tabular}

${ }^{1}$ Expert level microscopist typical performance in the range of $50-500 \mathrm{P} / \mu \mathrm{L}$ blood; malaria rapid diagnostic test (RDT) typical performance in the range of $100-200 \mathrm{P} / \mu \mathrm{L}$ blood. ${ }^{2}$ Two of 55 samples positive for P. falciparum had no record for parasite density (ND). ${ }^{3} 1$ of 73 samples positive for $P$. vivax had no record for parasite density (ND).

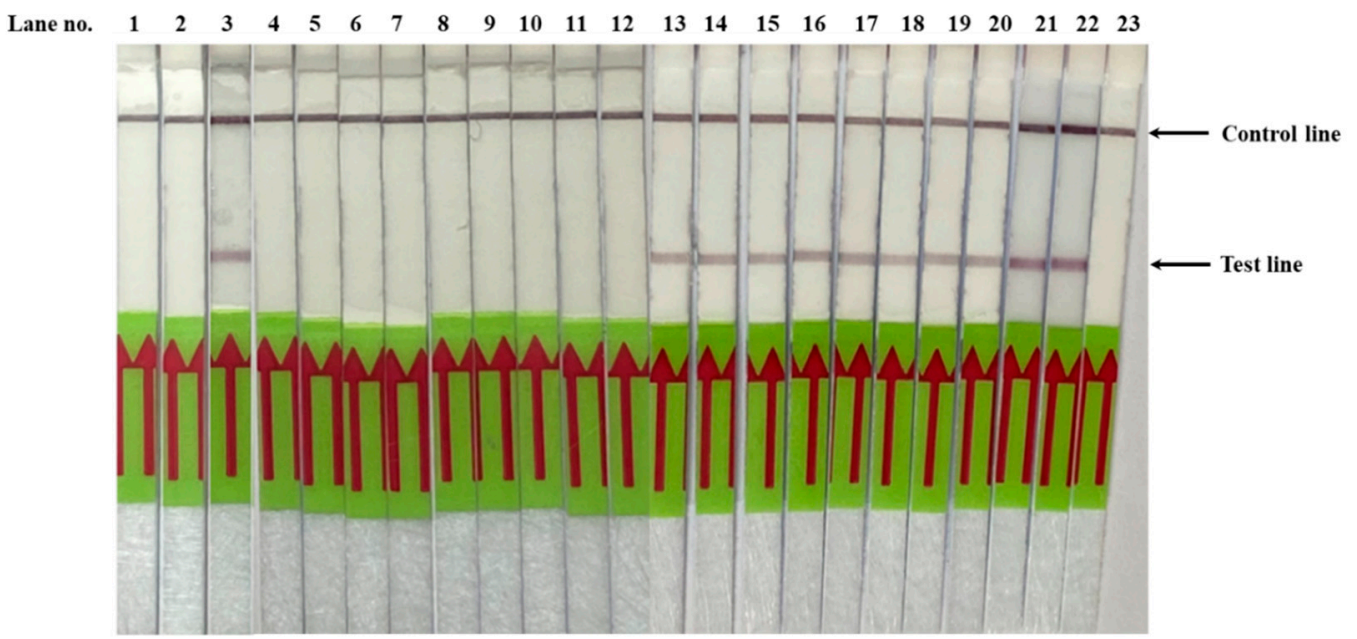

Figure 4. Validation of PfSNP-LAMP-LFD assay performed on genomic DNA extracted from clinical samples of P. falciparum and P. vivax. Lane 1 was negative control (no DNA template). Lanes 2 and 23 were negative control samples (20 ng of pUC18-Pfdhfr-TM4/8.2). Lanes 3 and 22 were positive control samples (20 ng of pUC18-Pfdhfr-V1/S). Lanes 4-12 were genomic DNA prepared from representative $P$. vivax-infected blood samples. Lanes 13-21 were genomic DNA prepared from representative $P$. falciparum-infected blood samples with parasite density as determined by microscopy examination to be $1298 \mathrm{P} / \mu \mathrm{L}, 926 \mathrm{P} / \mu \mathrm{L}, 17 \mathrm{P} / \mu \mathrm{L}, 12,418 \mathrm{P} / \mu \mathrm{L}, 2906 \mathrm{P} / \mu \mathrm{L}, 1341 \mathrm{P} / \mu \mathrm{L}, 7886 \mathrm{P} / \mu \mathrm{L}, 2835 \mathrm{P} / \mu \mathrm{L}$, and $1313 \mathrm{P} / \mu \mathrm{L}$, respectively.

\section{Discussion}

The primary objective of this study was to validate the PfSNP-LAMP-LFD using clinical samples while exploring the robustness of the method when performed under different conditions. Our results demonstrated that the PfSNP-LAMP-LFD could accurately distinguish SNP (AAT $\rightarrow$ ATT, N51I) associated with pyrimethamine resistance on 128 clinical samples with a broad range of parasite density from as low as 10 parasites/ $\mu \mathrm{L}$ of blood. The PfSNP-LAMP-LFD performance was comparable to typical 
LAMP-based protocols and other PCR-based protocols for distinguishing Plasmodium species [35]. For a more direct comparison, a recent publication by Chahar et al. reported a protocol for SNP-LAMP with hydroxynapthol blue indicator for the detection of S108N mutation in the Pfdhfr-ts gene with the detection limit of seven parasites $/ \mu \mathrm{L}$ at $60^{\circ} \mathrm{C}$ for $45 \mathrm{~min}$ [36].

In general, we noted that PfSNP-LAMP-LFD method, once optimized, was sufficiently robust to withstand some variations to the protocol, such as batch-to-batch variation of reagents, equipment and laboratory environment, and the experience level of laboratory technicians. Nonetheless, we observed that the efficiency of PfSNP-LAMP-LFD to distinguish mutant SNP from wild-type SNP was affected by the relationship between enzyme choice and the reaction cut-off time. In our observations at $63^{\circ} \mathrm{C}$, amplified signals from mutant samples could be detected within the 60-min mark for all versions of $B s t$ DNA polymerases, with Bst DNA polymerase large fragment showing the earlier peak signal, followed by Bst 2.0 DNA polymerase and Bst 2.0 WarmStart DNA polymerase. However, non-specific signals were detected in wild-type samples when the reactions extended well beyond the 60 -min mark. We observed an approximate delay of $25 \mathrm{~min}$ between the appearance of peak signals from mutant samples and wild-type samples for all three versions of the Bst DNA polymerases used in the study; this delay represented the window cut-off which PfSNP-LAMP-LFD could distinguish between the mutant and wild-type Pfdhfr-ts gene at codon 51. In previous PfLAMP and PfSNP-LAMP development efforts, the amplification reactions were optimized within the 60-min mark, in favor of a faster turnaround of reliable results; therefore, we did not observe the non-specific signals in prior experiments $[21,26]$.

Several factors can be attributed to non-specific amplification in LAMP products, including sample quality and partial hybridization of one or more LAMP primers to the fragmented DNA of target organisms or of host DNA. To ensure sample quality, purified genomic DNA samples were used for PfSNP-LAMP-LFD, and efforts were made to not exceed more than two freeze-thaw cycles of DNA samples and reagents. The design of the PfSNP-LAMP primer set relies on a single nucleotide base difference to distinguish between mutant from wild-type genotypes; the efficiency and stability of primers binding to the mutant sequences would be more favorable than binding to the wild-type sequences. This preferential binding can be leveraged by optimizing the relationship between enzyme and reaction time to promote favorable amplification from mutant sequences over wild-type sequences, thereby improving the sensitivity and specificity of PfSNP-LAMP. Similar observation patterns were made on the effects of enzyme choice and reaction temperature on the sensitivity and specificity of SNP-LAMP by Mohon et al. in their development of SNP-LAMP to detect the C580Y mutation in the Kelch13 gene corresponding to artemisinin-resistance in P. falciparum [37]. These observations further highlighted the key components to consider for successful development of SNP-LAMP, which included primer designs, enzyme choice, and cut-off reaction time.

The current $P f S N P-L A M P-L F D$ protocol includes a genomic DNA purification step, and thus requires the laboratories to be equipped with basic equipment, including microcentrifuge, temperature-control heating block or water bath, and pipetting instruments. Simplified sample preparation can improve the applicability of nucleic acid-based detection method as point-of-care diagnostics, particularly for use in more remote settings where malaria is endemic. However, this convenience in sample preparation can affect the quality of starting DNA templates, and consequently the limit of detection. Previous attempts to simplify DNA preparation showed a 10-fold difference in the limit of detection of PfSNP-LAMP-LFD, for example, when purified genomic DNA (LOD $=0.2 \mathrm{ng}$ of genomic DNA) was compared to non-purified genomic DNA (LOD $=2 \mathrm{ng}$ of genomic DNA in the presence of red blood cell lysate) [26]. The overall results and previous observations suggest that PfSNP-LAMP-LFD can provide consistent results for the detection of SNP associated with pyrimethamine resistance, which can be a proxy for treatment efficacy, particularly in areas where a sulfadoxine-pyrimethamine regimen is still in use. With increasing threats of multidrug-resistant malaria, PfSNP-LAMP-LFD can be used as part of a toolkit for a comprehensive molecular surveillance program to monitor known biomarkers for drug resistance to support evidence-based malaria treatment policies. 
Author Contributions: Author contributions include: conceptualization, S.Y., D.K. and S.B.; methodology, S.Y., D.K. and S.B.; validation, F.R.K.; formal analysis, S.Y., D.K., and S.B.; investigation, F.R.K., N.N., C.S. and S.W.; resources, J.S., W.N., N.K., and S.B.; writing—original draft preparation, S.B.; writing-review and editing, S.Y. and D.K.; funding acquisition, S.B. All authors have read and agreed to the published version of the manuscript.

Funding: This research was supported by Faculty of Science, Mahidol University, Bangkok, Thailand.

Acknowledgments: We are grateful for the patients who provided their informed consent. We thank the staff at malaria clinics and at Mahidol Vivax Research Unit, Faculty of Tropical Medicine, Mahidol University, Bangkok, Thailand for their supports in blood sample collection, microscopic examinations and nested PCR assay experiments.

Conflicts of Interest: The authors declare no commercial or financial conflict of interest. The funders had no role in the design of the study; in the collection, analyses, or interpretation of data; in the writing of the manuscript, or in the decision to publish the results.

\section{References}

1. WHO. World Malaria Report 2019; World Health Organization: Geneva, Switzerland, 2019.

2. WHO. WHO Seasonal Malaria Chemoprevention with Sulfadoxine-Pyrimethamine plus Amodiaquine in Children: A Field Guide. August 2013; World Health Organization: Geneva, Switzerland, 2013.

3. WHO. WHO Policy Brief for the Implementation of Intermittent Preventive Treatment of Malaria in Pregnancy Using Sulfadoxine-Pyrimethamine (IPTp-SP), April 2013 (rev. January 2014); World health Organization: Geneva, Switzerland, 2014.

4. Bzik, D.J.; Li, W.B.; Horii, T.; Inselburg, J. Molecular cloning and sequence analysis of the Plasmodium falciparum dihydrofolate reductase-thymidylate synthase gene. Proc. Natl. Acad. Sci. USA 1987, 84, 8360-8364. [CrossRef] [PubMed]

5. Triglia, T.; Cowman, A.F. Primary structure and expression of the dihydropteroate synthetase gene of Plasmodium falciparum. Proc. Natl. Acad. Sci. USA 1994, 91, 7149-7153. [CrossRef] [PubMed]

6. Cowman, A.F.; Morry, M.J.; Biggs, B.A.; Cross, G.A.; Foote, S.J. Amino acid changes linked to pyrimethamine resistance in the dihydrofolate reductase-thymidylate synthase gene of Plasmodium falciparum. Proc. Natl. Acad. Sci. USA 1988, 85, 9109-9113. [CrossRef] [PubMed]

7. Peterson, D.S.; Walliker, D.; Wellems, T.E. Evidence that a point mutation in dihydrofolate reductase-thymidylate synthase confers resistance to pyrimethamine in falciparum malaria. Proc. Natl. Acad. Sci. USA 1988, 85, 9114-9118. [CrossRef] [PubMed]

8. Bjorkman, A.; Phillips-Howard, P.A. The epidemiology of drug-resistant malaria. Trans. R. Soc. Trop. Med. Hyg. 1990, 84, 177-180. [CrossRef]

9. Peterson, D.S.; Milhous, W.K.; Wellems, T.E. Molecular basis of differential resistance to cycloguanil and pyrimethamine in Plasmodium falciparum malaria. Proc. Natl. Acad. Sci. USA 1990, 87, 3018-3022. [CrossRef]

10. Plowe, C.V.; Cortese, J.F.; Djimde, A.; Nwanyanwu, O.C.; Watkins, W.M.; Winstanley, P.A.; Estrada-Franco, J.G.; Mollinedo, R.E.; Avila, J.C.; Cespedes, J.L.; et al. Mutations in Plasmodium falciparum dihydrofolate reductase and dihydropteroate synthase and epidemiologic patterns of pyrimethamine-sulfadoxine use and resistance. J. Infect. Dis. 1997, 176, 1590-1596. [CrossRef]

11. Yuthavong, Y.; Vilaivan, T.; Chareonsethakul, N.; Kamchonwongpaisan, S.; Sirawaraporn, W.; Quarrell, R.; Lowe, G. Development of a lead inhibitor for the A16V+S108T mutant of dihydrofolate reductase from the cycloguanil-resistant strain (T9/94) of Plasmodium falciparum. J. Med. Chem. 2000, 43, 2738-2744. [CrossRef]

12. Wongsrichanalai, C.; Pickard, A.L.; Wernsdorfer, W.H.; Meshnick, S.R. Epidemiology of drug-resistant malaria. Lancet Infect. Dis. 2002, 2, 209-218. [CrossRef]

13. Nair, S.; Williams, J.T.; Brockman, A.; Paiphun, L.; Mayxay, M.; Newton, P.N.; Guthmann, J.P.; Smithuis, F.M.; Hien, T.T.; White, N.J.; et al. A selective sweep driven by pyrimethamine treatment in southeast asian malaria parasites. Mol. Biol. Evol. 2003, 20, 1526-1536. [CrossRef]

14. Roper, C.; Pearce, R.; Nair, S.; Sharp, B.; Nosten, F.; Anderson, T.J.C. Intercontinental spread of pyrimethamine-Resistant malaria. Science 2004, 305, 1124. [CrossRef] [PubMed]

15. Plowe, C.V.; Kublin, J.G.; Doumbo, O.K. P. falciparum dihydrofolate reductase and dihydropteroate synthase mutations: Epidemiology and role in clinical resistance to antifolates. Drug Resist. Updat. 1998, 1, 389-396. [CrossRef] 
16. Notomi, T.; Okayama, H.; Masubuchai, H.; Yonekawa, T.; Watanabe, K.; Amino, N.; Hase, T. Loop-mediated isothermal amplification of DNA. Nucleic Acids Res. 2000, 28, E63. [CrossRef] [PubMed]

17. Eiken Chemical Co., Ltd. Available online: https://www.eiken.co.jp/en/products/lamp/ (accessed on 6 November 2020).

18. Poon, L.L.; Wong, B.W.Y.; Ma, E.H.T.; Chan, K.H.; Chow, L.M.C.; Abeyewickreme, W.; Tangpukdee, N.; Yuen, K.Y.; Guan, Y.; Looareesuwan, S.; et al. Sensitive and inexpensive molecular test for falciparum malaria: Detecting Plasmodium falciparum DNA directly from heat-treated blood by loop-mediated isothermal amplification. Clin. Chem. 2006, 52, 303-306. [CrossRef] [PubMed]

19. Han, E.T.; Watanabe, R.; Sattabongkot, J.; Khuntirat, B.; Sirichaisinthop, J.; Iriko, H.; Jin, L.; Takeo, S.; Tsuboi, T. Detection of four Plasmodium species by genus and species-specific loop-mediated isothermal amplification for clinical diagnosis. J. Clin. Microbiol. 2007, 45, 2521-2528. [CrossRef] [PubMed]

20. Buates, S.; Bantuchai, S.; Sattabongkot, J.; Han, E.T.; Tsuboi, T.; Udomsangpetch, R.; Sirichaisinthop, J.; Tan-ariya, P. Development of a reverse transcription-loop-mediated isothermal amplification (RT-LAMP) for clinical detection of Plasmodium falciparum gametocytes. Parasitol. Int. 2010, 59, 414-420. [CrossRef]

21. Yongkiettrakul, S.; Jaroenram, W.; Arunrut, N.; Chareanchim, W.; Pannehpetch, S.; Suebsing, R.; Kiatpathomchai, W.; Pornthanakasem, W.; Yuthavong, Y.; Kongkasuriyachai, D. Application of loop-mediated isothermal amplification assay combined with lateral flow dipstick for detection of Plasmodium falciparum and Plasmodium vivax. Parasitol. Int. 2014, 63, 777-784. [CrossRef]

22. Jiang, Y.S.; Bhadra, S.; Li, B.; Wu, Y.R.; Milligan, J.N.; Ellington, A.D. Robust strand exchange reactions for the sequence-specific, real-time detection of nucleic acid amplicons. Anal. Chem. 2015, 87, 3314-3320. [CrossRef]

23. Yamanaka, E.S.; Tortajada-Genaro, L.A.; Pastor, N.; Maquieira, A. Polymorphism genotyping based on loop-mediated isothermal amplification and smartphone detection. Biosens. Bioelectron. 2018, 109, 177-183. [CrossRef]

24. Badolo, A.; Okado, K.; Guelbeogo, W.M.; Aonuma, H.; Bando, H.; Fukumoto, S.; Sagnon, N.; Kanuka, H. Development of an allele-specific, loop-mediated, isothermal amplification method (AS-LAMP) to detect the L1014F kdr-w mutation in Anopheles gambiae sl. Malar. J. 2012, 11, 227. [CrossRef]

25. Ding, S.; Chen, R.; Chen, G.; Li, M.; Wang, J.; Zou, J.; Du, F.; Dong, J.; Cui, X.; Huang, X.; et al. One-step colorimetric genotyping of single nucleotide polymorphism using probe-enhanced loop-mediated isothermal amplification (PE-LAMP). Theranostics 2019, 9, 3723-3731. [CrossRef] [PubMed]

26. Yongkiettrakul, S.; Kampeera, J.; Chareanchim, W.; Rattanajak, R.; Pornthanakasem, W.; Kiatpathomchai, W.; Kongkasuriyachai, D. Simple detection of single nucleotide polymorphism in Plasmodium falciparum by SNP-LAMP assay combined with lateral flow dipstick. Parasitol. Int. 2017, 66, 964-971. [CrossRef] [PubMed]

27. Itonaga, M.; Matsuzaki, I.; Warigaya, K.; Tamura, T.; Shimizu, Y.; Fujimoto, M.; Fumiyoshi, K.; Masao, I.; Murata, S. Novel methodology for rapid detection of KRAS mutation using PNA-LNA mediated loop-mediated isothermal amplification. PLOS ONE 2016, 11, e0151654. [CrossRef] [PubMed]

28. Parker, D.M.; Matthews, S.A.; Yan, G.; Zhou, G.; Lee, M.C.; Sirichaisinthop, J.; Kiattibutr, K.; Fan, Q.; Li, P.; Sattabongkot, J.; et al. Microgeography and molecular epidemiology of malaria at the Thailand-Myanmar border in the malaria pre-elimination phase. Malar. J. 2015, 14, 98. [CrossRef] [PubMed]

29. Kimura, M.; Kanako, O.; Liu, Q.; Zhou, M.; Kawamoto, F.; Wataya, Y.; Otani, S.; Yamaguchi, Y.; Tanabe, K. Identification of the four species of human malaria parasites by nested PCR that targets variant sequences in the small subunit rRNA gene. Parasitol. Int. 1997, 46, 91-95. [CrossRef]

30. Biswas, S.; Escalante, A.; Chaiyaroj, S.; Angkasekwinai, P.; Lal, A.A. Prevalence of point mutations in the dihydrofolate reductase and dihydropteroate synthetase genes of Plasmodium falciparum isolates from India and Thailand: A molecular epidemiologic study. Trop. Med. Int. Health 2001, 5, 737-743. [CrossRef] [PubMed]

31. Sugaram, R.; Suwannasin, K.; Kunasol, C.; Mathema, V.B.; Day, N.J.; Sudathip, P.; Prempree, P.; Dondorp, A.M.; Imwong, M. Molecular characterization of Plasmodium falciparum antifolate resistance markers in Thailand between 2008 and 2016. Malar. J. 2020, 19, 107. [CrossRef]

32. Wongsrichanalai, C.; Baracus, M.J.; Muth, S.; Sutamihardja, A.; Wernsdorfer, W.H. A review of malaria diagnostic tools: Microscopy and rapid diagnostic test (RDT). In Defining and Defeating the Intolerable Burden of Malaria III: Progress and Perspectives; Supplement to Volume 77(6) of AJTMH; Breman, J.G., Alilio, M.S., White, N.J., Eds.; American Society of Tropical Medicine and Hygiene: Northbrook, IL, USA, 2007. 
33. WHO. Policy Brief on Malaria Diagnostics in Low-Transmission Settings; World Health Organization: Geneva, Switzerland, 2014.

34. Wu, L.; Van den Hoogen, L.L.; Slater, H.; Walker, P.G.T.; Ghani, A.C.; Drakeley, C.J.; Okell, L.C. Comparison of diagnostics for the detection of asymptomatic Plasmodium falciparum infections to inform control and elimination strategies. Nature 2015, 528, S86-S93. [CrossRef]

35. Sattabongkot, J.; Suansomjit, C.; Nguitragool, W.; Sirichaisinthop, J.; Warit, S.; Tiensuwan, M.; Buates, S. Prevalence of asymptomatic Plasmodium infections with sub-microscopic parasite densities in the northwestern border of Thailand: A potential threat to malaria elimination. Malar. J. 2018, 17, 329. [CrossRef]

36. Chahar, M.; Anvikar, A.; Valecha, N. Development and evaluation of a novel HNB based isothermal amplification assay for fast detection of Pyrimethamine resistance (S108N) in Plasmodium falciparum. Int. J. Environ. Res. Public Health 2019, 16, 1635. [CrossRef]

37. Mohon, A.N.; Menard, D.; Alam, M.S.; Perera, K.; Pillai, D.R. A novel single-nucleotide polymorphism Loop Mediated Isothermal Amplification assay for detection of Artemisinin-resistant Plasmodium falciparum malaria. Open Forum Infect. Dis. 2018, 5. [CrossRef] [PubMed]

Publisher's Note: MDPI stays neutral with regard to jurisdictional claims in published maps and institutional affiliations.

(C) 2020 by the authors. Licensee MDPI, Basel, Switzerland. This article is an open access article distributed under the terms and conditions of the Creative Commons Attribution (CC BY) license (http://creativecommons.org/licenses/by/4.0/). 